\title{
Research on the Pre-Entrance Education of Freshmen
}

\author{
Li Xiaorui", Zhou Peng \\ School of Communication, Mianyang Teachers' School, Mianyang, China
}

\section{Email address:}

1251644384@qq.com (Li Xiaorui), 13154192qq.com (Zhou Peng)

*Corresponding author

\section{To cite this article:}

Li Xiaorui, Zhou Peng. Research on the Pre-Entrance Education of Freshmen. Science Innovation. Vol. 8, No. 6, 2020 , pp. 166-169. doi: 10.11648/j.si.20200806.12

Received: December 21, 2020; Accepted: January 8, 2021; Published: January 18, 2021

\begin{abstract}
As the link between high school and university, College entrance education plays an extremely important role in helping students quickly and effectively change roles and ideas, enhance their adaptability, and reshape their learning goals. Entrance education is also a compulsory link in the cultivation of college students in China. With the continuous development of the society and the entrance of the post-2000 freshmen, the traditional entrance education, which focuses on concentrated learning, has gradually shown that it can not meet the needs of freshmen. There is a great contrast between their distinctive personality characteristics and traditional entrance education in teaching methods, time arrangement and communication platform choice. Therefore, in view of this kind of situation, this paper will further meet the actual needs of freshmen adaptability from the perspective of the content and form selection in the pre-entrance education for freshmen. Through literature survey and comparison, this paper hopes to find an effective way to break through the time and space limitation of the current concentrated teaching, so as to further promote the effectiveness of college entrance education, realize the effective method of education purpose, and help college freshmen to adapt to the new environment as soon as possible and better complete the role transformation.
\end{abstract}

Keywords: Freshmen, Entrance Education, Pre-Research

\section{大学新生入学教育前置研究}

\author{
李晓飸”, 周鹏 \\ 绵阳师范学院传媒学院, 绵阳, 中国 \\ 邮箱 \\ 1251644384@qq.com (李晓睿)，13154192qq.com（周鹏）
}

摘要: 大学入学教育作为衔接高中与大学的纽带, 其在帮助学生快速有效转换角色、观念, 增强适应性, 重塑学习目 标等方面有着极其重要的作用。因此入学教育也作为国内高校学生培养的必修环节而遍存在。但是随着社会的不断发 展以及“ 00 后” 新生的入校, 他们鲜明的个性特征与传统入学教育在讲授方式、时间安排及传播平台的选择方面存在巨 大的反差, 传统的入学教育逐步显现出不能满足新生需求的态势。因此针对此类情况, 本文将从进一步满足新生适应 性的实际需求角度出发, 就新生入学教育前置中的内容和形式选择问题进行探讨。本文拟通过文献调查和比较的方法 希望能探究出突破目前集中教学时空限制的有效方式, 以此来进一步推动提升大学入学教育实效, 实现教育目的有效 方法, 帮助大学新生尽快的适应新的环境, 更好的完成角色转化。

关键词: 大学新生, 入学教育, 前置研究 


\section{1. 引言}

大学入学教育是新生进入大学的第一课, 其意义在于 帮助新生完成从高中到大学的转变, 从而尽快适应大学生 活, 为高校实现“立德树人”目标奠定基础。因此不管是从 学生的学习还是从学校的教育角度出发, 入学教育的重要 性都不言而喻。但是随着“ 00 后”新生的入校, 他们鲜明的 个性特征对于传统的入学教育提出了严峻的考验, 教育效 果受到了严重的冲击。[1]特别是“短期集中式”的入学教育 模式更是受到学生的排斥。因此为大力推进“三全育人”的 教育理念, 高校的教育工作者不得不重新思考“全程育人” 的更深层次涵义, 重新设置入学教育的时间段, 以入学之 初的短期集中培训为基础, 将教育的时限往前、后进行纵 向延伸, 入学前的前置教育, 入学教育后的持续教育就显 得尤为必要。就现有研究来看, 学者们对于传统的入学教 育存在的弊端研究是比较透彻的, 针对入学教育前置也有 一些较为新颖的观点, 其中“三方互动式入学教育模式”[2] 是目前入学教育前置研究中引用较多的观点, 同时对于高 校入学教育的具体实施也有许多的见解, 但是笔者认为目 前学界对于该问题的研究不管是从内容还是思路上都有 一定的局限。因此本文将就入学前的前置教育内容与方式 等展开讨论, 以期能够突破目前研究的禁锢, 探索出一条 适合当代大学新生的入学教育模式, 帮助大学新生完成角 色转换。

\section{2. 大学新生入学教育的现状}

高校的“入学教育”通常分为三个部分：集中教育（包 括校纪校规校史教育、专业认同教育、心理教育、安全教 育等）、军事理论教育以及军训。[3]三部分内容共同构成 高校入学教育体系。就目前国内的情况来看, 高校对于新 生入学教育非常重视, 部分高校在长期的实践中还推出了 各种行之有效的教育模式，如“导师制教育”，“生态位”教 育、“体验式入学教育模式”。[4]同时入学教育作为高校教 育的必修环节, 被广泛纳入到了培养方案的必修课体系 中。

入学教育作为学生转变的桥梁, 其开设是新生充分 认识大学的需要; 是学生适应新的教学理念的需要; 是 学生独立成长的需要。[5]尽管如此, 由于各大高校主客 观因素的影响, 目前我国高校的入学教育仍然存在教育 管理制度不健全、多元的教育主体缺乏合力, 教育内容 泛化, 教育形式单一, 教育时间集中等普遍问题。[6]特 别是教育时间与形式问题尤为突出。就现行的入学教育 情况来看, 短期集中式教育情况普遍。这一情形主要是 由于培养方案中对于专业教育过度强调, 过多的课时安 排缩减了入学教育时长, 加之师资不足等原因很多高校 的入学教育披着重视的外衣却流于形式, 教育效果不明 显。针对这一情况, 越来越多的学者开始着手研究怎样 延长入学教育时长, 提升入学教育时效的问题在这种情 况下, 前置教育理念被提出。但是就目前的研究成果来 看, 研究还有待进一步的深入。

\section{3. 入学教育前置的可行性和必要性}

根据目前学界对于大学新生入学教育前置的研究结 果可以了解, “前置” 是指将入学教育的内容前置到大学录 取与入学之间的“空闲”期完成。[7]这样的设置方式一方面 是因为学生有充足的时间和高昂的学习激情; 另一方面也 可以充实学生高考后空虚的生活, 让准大学生们提前做好 进入大学的准备。

\section{1. 教育前置的可行性}

充足的“闲置”时间。从高考结束到大学录取报到, 这 期间的时间空挡大概在2-3个月。因学生刚刚结束了高强 度的高中学习和激烈的高考, 因此绝大多数学生会理所当 然的把这段时间用于“休养”，几乎不会安排学习相关的事 情。家长也因高考的结束而默许学生的放松。故这两个月 中, 大多数学生会把吃喝玩乐当做生活的主题。因此这段 时间对于准大学生们来说是一段内心毫无压力的“闲置” 时间。适宜学习的心境。“苦高中, 要大学”这是高中老师 激励学生的“名言警句”, 不少学生在此警句的鼓励下顺利 考进大学。“苦”的生活结束也就预示着“要”的机会已经到 来, 因此准大学生们在 “要”大学的心态推动下, 对于大学 的向往就显得尤为强烈, 跟大学相关的一且信息都能调动 起他们学习的好奇心。故此时前置部分入学教育的内容既 能充分满足学生强烈的好奇心又能实现教育的目的。

\section{2. 教育前置的必要性}

新生入学教育作为从高中到大学的过渡教育 [8]它承 担着辅助学生认知大学规则和内容的职责, 过渡教育的成 功与否直接关系到学生整个大学期间的管理和学习, 关系 到学生的成长成才, 其重要性十分突出。

同时笔者长期从事学生一线管理工作，从大量的实践 中发现大一新生挂科率居高不下, 生活、学习不适应情况 频发。究其原因大多数新生对大学生活、学习的认识和思 想准备不足是其中重要的原因之一。针对这一现象, 为有 效规避目前高校入学教育“时间紧、任务重”的弊端, 前置 入学教育有助于进一步改善大一新生适应不良而带来的 诸多问题。

\section{4. 新生入学教育前置的内容选择}

前置入学教育是高校系统的集中教育和持续的入学 后教育的重要组成部分, 其内容选择不仅要与集中教育形 成整体, 要符合前置教育实施的形式, 更要从提高新生报 到率等角度进行思考, 只有做到这几点才能充分的发挥前 置教育的作用, 形成整体的学习效果。

\section{1. 校史校情教育}

校史校情是高校德育教育的重要资源, 它既是学校文 化、学校精神、学校传统独特形成和发展过程的体现, 也 是中国革命、社会主义建设和改革发展的缩影, 折射出国 
史国情。[9]因此将校史校情教育作为前置教育的内容之 一, 在进行德育教育的同时, 提高新生对学校的整体认识; 在培养认同感和归属感的同时, 也有助于提高新生整体的 报到率，切实发挥教育前置的作用。

\section{2. 适应性教育}

如果说新生入学教育是大学第一课, 那么适应性教育 就应该是开篇第一章, 学校必须在这一章节中教会学生如 何实现自身的华丽转变, 这种转变不仅是身份的转变, 更 是心理和思维的转变。此外有研究表明: 大学新生的总体 适应水平低于全国大学生常模。[10]因此无论是从学校的 教育出发还是学生的成长需要, 尽早的开展新生适应性教 育, 让新生在入校之前开始了解大学生活的特点, 引导新 生做好人际关系、校院生活、学习以及个人情绪等方面的 适应准备将有助于新生更快的融入大学生活。

\section{3. 学科专业教育}

分学科教育是高校教育不同于其他阶段教育的显著 地方。高校因教育学科众多, 专业化程度较高且狠多学生 及家长对相关专业的了解度不够, 因此容易在未报到之前 产生复读、转专业、抵触学习等念头, 因此将学科专业教 育提前不仅可以帮助学生和家长了解所报专业, 减少因盲 目无知作出的决定所带来的遗憾, 而且可以激发学生的科 研和学习热情, 加强学生对本专业的信心。[11]从而提高 专业接受度, 从而提高报到率, 降低转专业率。

与此时同让学提前接受科学合理的专业指导, 不仅有 利于引导学生做好长远的专业学习计划, 找准切入点, 在 专业上有所建树, 又能帮助学生搭建好“嫁接”相近专业, “外接”相关专业的基础, 将知识的迁移与融汇贯通效果最 大化。[12]此外学生对于专业有了科学的认识和准确的定 位不仅为好的就业奠定了基础, 也利于教师专业教育的开 展和学科建设和持续发展。

\section{5. 新生入学教育前置的实施}

入学教育前置不仅是对当下传统教育理念的创新, 也 是延伸入学教育时空的一种有效方式。但是高校在前置入 学教育实施的过程中必须要认清前置教育与传统教育的 不同之处, 要针对前置教育的特殊性进行合理有效的形式 选择。

\section{1. 多样的教育形式}

“00后”的一代是伴随着网络而成长的一代, 他们对于 网络的接受度和要求均较高。有人就入学教育的载体和形 式需求做了调查, 数据显示: 高达 $59 \%$ 的学生认为在入学 教育中除了微信公众号和网站外, 高校还应该在抖音、B 站、短视频等方面做更多的努力。[13]

虽然目前我国高校几乎都建立了以学校宣传平台为 中心, 以各职能部门和二级学院宣传平台为支点的全方 位、立体式宣传体系, 官方的网站、微博、微信、抖音内 容丰富, 更新速度也较快, 但是各大高校更多的还是用于 宣传而非教育。因此校院两级应该统一部署, 根据平台的
不同特性, 制定系统的, 形式多样的入学教育专题内容, 集中投放，形成整体效应。

\section{2. 提前开放网络课程}

网络课程作为互联网时代新型的教育模式, 突破了传 统的教育理念, 而其传播范围大, 灵活性高, 较高的课程 质量以及有助于增强学生学习主动性的优势深受当下学 生的喜爱。[14]它与宣传平台所推出的短、平、快的教育 内容相比, 其专业性和系统性更强, 因此高校应该充分有 效的利用现有的网络在线课程, 提前将专业性较强且必修 的入学教育部分课程向新生开放, 如心理健康教育、安全 教育、理想信念教育等。这类教育其系统性较强、所需时 间较长, 特别是将心理健康教育提前, 能让学生家长也参 与其中, 让新生在逐步适应自主学习的方式的同时, 构建 起家长、学生、学校三方互动和理解的基础, 方便家校合 作的进一步推进, 也能很好的解决各高校师资不足的问 题。

\section{3. 善用体验式教学}

体验式教学是强调以学生为主体的自主探究方式, 通 过创设情境使学生在亲身经历中形成知识框架, 增长见 识, 主动融入, 在提升经验的同时获得能力。[15]因此在 前置的入学教育中, 各院系可以从学生活动、学科竞赛、 社会实践、专业实习等方面出发, 选择本学院中特色活动、 优秀学生、校友等, 将他们的事迹做成系列推文向新生推 送。也可以让他们“现身说法”, 利用抖音、短视频等形式 将他们的大学故事讲给新生听, 充分发挥朋辈教育作用。

\section{6. 结论}

就高校新生入学教育的现状而言, 时间紧、任务重仍 然是亟待解决的首要问题, 因此为打破时空界限, 利

用网络平台前置入学教育是正确的选择, 也是高校教 育创新、改革的必由之路。新生入学教育是一个长期性、 系统性的工作, 高校要在尊重入学教育规律性的基础上, 大胆改革创新, 不断提升入学教育的质量和效果, 才能实 现高校“立德树人”目标。

\section{致谢}

本文是四川省2020年网络思想政治教育研究一般课 题《基于互联网思维的大学新生入学教育前置研究》, 项 目编号: CJWSZ20-26的阶段性研究成果之一。

\section{参考文献}

[1] 彭晶,高校新生入学教育的实践路径研究[J].沈阳干部学刊, 2020(10):50。 
[2] 王智广,鲍震宇, 大学新生入学教育创新性研究[N].内蒙古农 业大学学报（社会科学版），2013(1):113。

[3] 彭晓清,浅新时代高职院校新生入学教育 [J].当代教育实践 与教学研究, 2020(9):92。

[4] 邓吕高, 汤硈,地方高校新生入学教育对策[J].教育探索, 2014(3):107。

[5] 王培森, 林志峰, 蓝庆专, 浅谈如何做好大学生新生入学教 育 $[\mathrm{J}]$.南方论刊,2020（9）:92。

[6] 董文伟,新时代高校新生入学教育的路径探析[J].教育现代 化, 2020(6):180。

[7] 间海水, 大学新生教育 “前置”刍议 [J]. 黑龙江高教研究, 2016 (6):88-90。

[8] 魏青, 阮恒,高校入学教育的扩展: 高中-大学过渡教育 [J]. 黑龙江高教研究, 2015(2):31。
[9] 柳礼泉, 唐珍名, 高校德育视野下的校史校情教育[J].高校 理论战线, 2011（3）:52。

[10] 张春桃,大学新生心理适应能力调查与研究 [J].才智, 2020 (7) :102。

[11] 丛丹斌, 孙永川,大学新生入学教育的思考与实践 [J].教育现 代化, 2019(11):171。

[12] 马媛,简议高校新生入学教育[N].扬州大学学报（高教研究 版），2003(6):7。

[13] 李斯明, 居学明,比较视野下高校新生入学教育场域探索 $[\mathrm{N}]$. 淮北职业技术学院学报, 2020(10):29

[14] 刘岩,基于网络课程对推进教育模式改革的探讨 [J].教育现 代化, 2018(4):65。

[15] 爽丽,体验式教育模式在高校新生入学教育中的运用[C].中 国会议,2020万知科学发展论坛论文集, 2020(6)。 